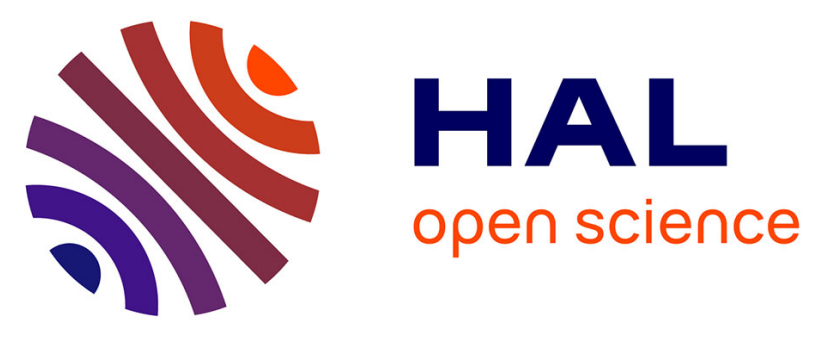

\title{
Passive mesenterico-saphenous shunt: An alternative to portocaval anastomosis for tailored portal decompression during liver transplantation
}

François Faitot, Pietro Addeo, Camille Besch, Baptiste Michard, Constantin Oncioiu, Bernard Ellero, Marie-Lorraine Woehl-Jaeglé, Philippe Bachellier

\section{To cite this version:}

François Faitot, Pietro Addeo, Camille Besch, Baptiste Michard, Constantin Oncioiu, et al.. Passive mesenterico-saphenous shunt: An alternative to portocaval anastomosis for tailored portal decompression during liver transplantation. Surgery, 2019, 165, pp.970 - 977. 10.1016/j.surg.2018.10.036 . hal-03486740

\author{
HAL Id: hal-03486740 \\ https://hal.science/hal-03486740
}

Submitted on 20 Dec 2021

HAL is a multi-disciplinary open access archive for the deposit and dissemination of scientific research documents, whether they are published or not. The documents may come from teaching and research institutions in France or abroad, or from public or private research centers.
L'archive ouverte pluridisciplinaire HAL, est destinée au dépôt et à la diffusion de documents scientifiques de niveau recherche, publiés ou non, émanant des établissements d'enseignement et de recherche français ou étrangers, des laboratoires publics ou privés.

\section{(ㅇ)(1) $\$$}

Distributed under a Creative Commons Attribution - NonCommerciall 4.0 International 
Version of Record: https://www.sciencedirect.com/science/article/pii/S0039606018307529

Manuscript_74b5fb61542d90d1be6882bf89e07e3d

Passive mesenterico-saphenous shunt: an alternative to portocaval anastomosis for tailored portal decompression during liver transplantation

François Faitot $M \mathrm{MPhD}^{1,2}$, Pietro $\mathrm{F}$ Addeo $\mathrm{MD}^{1,2}$, Camille Besch $\mathrm{MD}^{1}$, Michard Baptiste $\mathrm{MD}^{1}$, Constantin Oncioiu $\mathrm{MD}^{1}$, Bernard Ellero $\mathrm{MD}^{1}$, Marie-Lorraine Woehl-Jaeglé $\mathrm{MD}^{1}$, Philippe Bachellier $\mathrm{MDPhD}^{1}$

${ }^{1}$ Hepatobiliopancreatic Surgery and Transplantation Department, Hopital de Hautepierre, Hopitaux Universitaires de Strasbourg, France

${ }^{2}$ Laboratoire ICube, UMR7357, University of Strasbourg, France

Correspondence and reprint request :

Dr François Faitot, MDPhD

Hopitaux Universitaires de Strasbourg

Hepatobiliopancreatic Surgery and Transplantation Department, 1 avenue Molière, 67000 Strasbourg;

Email address : francois.faitot@chru-strasbourg.fr

Phone number: +3388128650

Fax number: +338127286

The authors declare no conflict of interest and no financial support for this study

Original communication 
Abstract

Background: temporary portocaval shunt (PCS) has a positive impact on short-term outcomes after liver transplantation (LT). An alternative to PCS is a distal passive decompression through mesenterico-saphenous shunt (MSS). The purpose of this study was to compare outcomes of these 2 types of surgical portosystemic shunt and discuss their respective place during the anhepatic phase.

Method: patients transplanted with portal decompression during a 4-year period were included. Patients were compared according to 2 types of surgical decompression techniques: $\operatorname{PCS}(n=44)$ and $\operatorname{MSS}(\mathrm{n}=77)$. Spontaneous $>5 \mathrm{~mm}$ portosystemic shunts were described as absent, non persistent, distal or proximal. Intraoperative portal pressure variations and in-hospital course were compared between the 2 groups with special attention on the impact of competing spontaneous and surgical shunts.

Results: MSS and PCS showed a comparable hemodynamic efficiency with no significant difference in terms of portal pressure variations. There was no significant difference in terms of reperfusion syndrome $(p=0.956)$, transfusion rate $(p=0.575)$, renal failure $(p=0.239)$ nor early allograft dysfunction $(p=0.976)$. There was a significantly higher risk of early allograft dysfunction when competing surgical and spontaneous shunts were used $(p=0.002)$ with a lesser hemodynamic efficiency (ANOVA test; $\mathrm{p}=0.04)$

Conclusion: portacaval or mesenterico-saphenous shunts offer similar hemodynamic efficiency without impacting on the outcomes after liver transplantation. Their respective place and the place of portal decompression should be discussed in regard to the presence of portal thrombosis and preexisting portosystemic shunts. Evaluation of the anatomy and the efficiency of these shunts may guide tailored portal decompression. 
Introduction

During the anhepatic phase of liver transplantation, splanchnic venous congestion may occur. Whereas portal decompression was systematically applied in the beginning of liver transplantation through veno-venous bypass, the advent of vena cava conservation has led to a decreased attention to this issue. However, Belghiti et al. ${ }^{1}$ and Tzakis et al. ${ }^{2}$ promoted the use of temporary portocaval shunt to avoid venous congestion during this phase of transplantation. Its use has been widely diffused but portal decompression is still not always practiced over the world.

Many studies among which randomized controlled studies have shown beneficial impact of portal decompression on transfusion rate, post-transplantation renal failure and even long-term outcomes. ${ }^{3}$ The possibility to dissect the liver without portal inflow may explain a large part of its advantages. Moreover the use of portal decompression has shown to be associated to a decreased risk of reperfusion syndrome (RPS). The impact of RPS on transplantation outcomes has been demonstrated but its physiopathology is not clear. ${ }^{4}$ One of the main hypothesis is a decreased splanchnic congestion responsible for decreased intestinal barrier alterations and lesser metabolic disturbances. Reduction of endotoxinemia may be a mechanism for the observed benefit given the significant impact of endotoxinemia during liver transplantation. ${ }^{5}$ However the use of portal decompression is still a matter of debate. It is not uniformly used even though good level of evidence tends to promote its use. ${ }^{6}$ On the other hand, teams reported their experience without need of portal decompression at all. ${ }^{7,8}$ Some technical arguments against portocaval anastomosis have been raised. Indeed portocaval anastomosis may be problematic in cases of portal thrombosis and its realization needs pedicle dissection which can tricky in case of history of cholecystectomy or other supramesocolic surgery or in case of large segment 1 . In this view, alternatives to classical portocaval shunt (PCS) that avoid pedicle dissection might be interesting. We present herein a passive mesenterico-saphenous shunt (MSS) as distal shunt in alternative to PCS. 
Another question that has not been addressed in the literature is the hemodynamic efficiency of portal decompression especially in patients with already existing porto-systemic shunt. Indeed the presence and most importantly the anatomy of the spontaneous shunt may directly impact the benefit of portal decompression.

The goal of this study was to evaluate the hemodynamic efficiency of surgical shunts according to their anatomy and to identify some parameters to tailor portal decompression during liver transplantation when needed. We tested the hypothesis that all spontaneous shunts are not equally efficient during the anhepatic phase leading to a need for tailored portal decompression according to their anatomy. Absence of portal decompression in the absence of efficient shunts as well as competing spontaneous and surgical shunts when completed may alter graft function.

Material and methods

\section{Patient's selection and liver transplantation}

All patients transplanted between January 2014 and January 2017 were retrospectively analyzed after approval by the University of Strasbourg ethical committee in accordance to 1975 Declaration of Helsinki. Patients that benefited from portocaval shunt or mesenterico-saphenous shunt during this period were included in an efficiency analysis to compare the 2 types of surgical shunts. In addition, patients for whom portal pressure and central venous pressure were available before and within 5 minutes after portal clamping and shunt opening were included in a hemodynamic study. $\underline{A}$ group of 92 patients not undergoing portal decompression during the same study period was used as a control population.

Patients were selected for liver transplantation after standard work-up according to the EASL guidelines for liver transplantation. Patients with HCC were listed when they met the French 
multicentric study criteria according to Duvoux's score. Patients with alcoholic cirrhosis and acute alcoholic hepatitis were considered for transplantation when they met the already published criteria.

Liver transplantation was performed with vena cava preservation in all cases. The use and type of portal decompression was let to the surgeon's discretion. The graft was reperfused after wash out with albumin at room temperature and after the completion of caval and portal anastomosis. Liver graft were classically reperfused with caval and portal unclamping before arterial anastomosis was performed.

Spontaneous shunts were ligated in case of poor portal flow after arterial reperfusion evaluated on visual flow at unclamping and Doppler ultrasonography waves.

\section{Surgical portal decompression technique (Figure 1)}

Portocaval anastomosis was performed according to already published technique. ${ }^{1}$ Briefly a terminolateral portocaval anastomosis was fashioned with 2 hemi-sutures of 5-0 Prolene and unclamped during the whole anhepatic phase. Portal pressures were measured by inserting a 23Fr catheter connected to the central venous pressure transducer - in the portal trunk.

Mesenterico-saphenous shunt was performed by dissecting the inferior mesenteric vein (IMV) a few centimeters under the duodeno-jejunal angle. IMV was ligated on its proximal part to insert a $16 \mathrm{Ch}$ Argile canula (Covidien, France) as during liver procurement. The canula was inserted $2-3 \mathrm{~cm}$ into the IMV in order not to completely occlude the splenic vein and to let clear the hepatic pedicle. A second 16Ch Argile canula was inserted in the saphenous vein after dissection of the Scarpa area. The cannulas were connected through a $25 \mathrm{~cm} 30 \mathrm{Ch}$ tubular drain in order to avoid kinking of the shunt. In order to continuously measure portal pressure during liver transplantation a $1 / 4-1 / 4$ adaptor shunt (Diderot, France) was used to connect the mesenteric cannula to the tubular drain. Pressure head captor was connected to the anesthesiology machine to measure portal pressure. This shunt 
achieves a left-sided distal surgical shunt in opposition to portocaval shunt which achieves a proximal shunt. Time needed for realization is between 5-15 minutes.

\section{Spontaneous porto-systemic shunt analysis}

Spontaneous porto-systemic shunts were analyzed on pre-transplant CT scans that was systematically practiced. Portal phase was used for the analysis with frontal and sagittal MIP reconstruction in order to detail the type of shunt. The anatomical description of the shunts were used according to Saad et al. ${ }^{9}$ In brief, the 6 types of shunts were : umbilical vein (UV), indirect splenorenal shunt through the retrogastric venous collaterals, direct splenorenal shunt (SRS), left gastric shunt (LGS), TIPS, mesenteric and retroperitoneal shunts (inferior or superior MS/RPS). The shunt was considered significant when its diameter was more than $5 \mathrm{~mm}$. Shunts were first classified according to the caval territory of drainage (superior or inferior vena cava). Second, shunts were classified according to their persistence during liver transplantation after portal clamping. Hence ombilical vein shunts and TIPS were considered non persistent shunts (NPS) whereas splenorenal, left gastric shunt, mesenteric and retroperitoneal shunts were considered persistent shunts (PS). Among persistent shunts, left-sided shunts (SRS, IMS/RPS) were termed distal and distinguished from rightsided shunts (LGS, SMS) which were termed proximal.

Definitions

Early allograft dysfunction was defined according to Olthoff's criteria : day 7 bilirubin $>170 \mu \mathrm{mol} / \mathrm{L}$, day 7 INR $>1.6$ and/or peak transaminases during the $1^{\text {st }}$ week $>2000 .{ }^{10}$

Primary non function was defined as the necessity of retransplantation or death within the first 7 days after LT after excluding surgical complications.

Design of the study 
Among 232 transplanted patients and after excluding associated kidney, lung and heart transplant as well as emergency retransplantation, 121 patients (52\%) having received portocaval shunt or mesenterico-saphenous shunt were included and compared in terms of intra-operative and shortterm outcome in a retrospective analysis. The hemodynamic efficiency of portal decompression was evaluated in a series of 48 patients for whom portal pressure measurements were available before and after clamping of the portal vein. A group of 92 patients transplanted without portal decompression during the same period was used as control.

The impact of the presence and type of spontaneous portosystemic shunts was evaluated on the hemodynamic efficiency of portal decompression. Outcomes were compared according to the type of portal decompression used and the anatomy of spontaneous shunts.

In order to further refine the indications for each technique, competing surgical and spontaneous shunts were considered at risk of graft dysfunction due to a lesser efficiency. Competing surgical and spontaneous shunts were considered when a persistent spontaneous shunt was in the opposite territory as the surgical shunt. For patients with complete portal thrombosis, mesenterico-saphenous shunt was considered the optimal technique. Decompression strategy was considered as potentially inefficient when no shunt was made in the absence of a persistent shunt or when a competing surgical shunt was faschioned.

\section{Statistical analysis}

The results are reported as mean \pm standard deviation or median (range) for continuous variable according to the distribution of the variable. Continuous variables are compared between groups using a paired Student t-test or a Mann-Whitney U-test as appropriate. Categorical variables are compared using a Chi-square test. ANOVA analysis was used when more than 2 groups had to be compared. Significant difference between groups was considered when p-value $<0.05$. Statistical analysis were performed with Statview software (version 5.0 for Windows; SAS Institute, Cary, NC) 
Results

The demographic characteristics of the 213 studied patients according to the type of surgical decompression are reported in table 1. Of note, patients not undergoing portal decompression had less severe liver disease as shown by lower MELD score at LT and had significantly more frequently preexisting shunts and portal thrombosis $(\mathrm{p}=0.0005)$.

\section{Hemodynamic study}

Hemodynamic efficiency of spontaneous portosystemic shunts

Portal clamping was associated to a median increase in portal pressure of $11 \mathrm{mmHg}(-6-43)$. Of note, 2 patients presented with a decrease in portal pressure at portal clamping, one of whom had RenduOsler disease and the other a $5 \mathrm{~mm}$ indirect splenorenal shunt. Portal pressure elevation was significantly lower in patients presenting persistent shunts $(4.7 \pm 6)$ compared to patients with non persistent shunts $(12.1 \pm 8 ; p=0.047)$ or no spontaneous shunt $(15.8 \pm 11 ; p=0.001)$. There was no significant difference in portal pressure elevation between patients with no shunt or non persistent shunt $(\mathrm{p}=0.282)$. In patients with persistent shunts, there was a trend towards better hemodynamic efficiency of distal shunts compared to proximal shunts (namely left gastric vein and superior mesenteric shunts) showed by a lower increase in portal pressure at portal clamping ( $8 \pm 7$ vs 19 $\pm 1 ; p=0.051)$.

Hemodynamic efficiency of surgical portosystemic shunts (table 2)

After the unclamping of a surgical temporary shunt, the mean portal decrease was $16.7 \mathrm{mmHg}(-5$ 25). The 2 types of shunts showed a similar hemodynamic efficiency as portal pressure decreased of $17.7 \pm 11$ and $15.4 \pm 10$ ( $p=0.517)$ for mesenterico-saphenous shunt or portocaval shunt respectively. 
When analyzing only patients without persistent shunt, there was still no difference between the two types of shunts $(p=0.962)$.

Portal pressure decrease was compared for each type of surgical shunt according to the type of preexisting shunts. For portocaval shunt, the presence of distal shunt (mostly splenorenal shunt) was associated with a significantly lower portal pressure decrease ie lesser hemodynamic efficiency compared to proximal shunts $(\mathrm{p}=0.006)$. For mesenterico-saphenous shunt, there was no significant difference in portal pressure decrease although it tended to be more efficient in the absence of spontaneous persistent shunt $(\mathrm{p}=0.194)$. (Table 3 ) (Figure 2 )

Impact of surgical decompression technique on intra- and post-operative course (table 4)

There was no significant major differences in terms of intraoperative course between portocaval shunt or mesenterico-saphenous shunt except for the intervention duration which was longer in the mesenterico-saphenous shunt $(p=0.011)$. Intraoperative transfusions were comparable between the groups regarding RBC, FFP and platelets. Of note, lactate levels at reperfusion was higher in the group with mesenterico-saphenous shunt than with portocaval shunt without significant impact in terms of reperfusion syndrome or postoperative outcome.

Indeed the rate of medical complications were similar between both groups and the median hospital stay was comparable $(p=0.99)$. There was a non significant trend towards lower day7 bilirubin and INR in the mesenterico-saphenous shunt group but this did not reach significance.

Patients without portal decompression had a higher quantity of transfusion $(p=0.049)$ and a trend towards higher 90-day mortality $(\mathrm{p}=0.061)$.

When considering only shunted population, early allograft dysfunction was significantly more frequent $(67 \%$ vs $13 \% ; p=0.002)$ when the optimal shunt was not used. The difference was mainly observed due to higher day 1 transaminases. (Figure 3) When considering also non shunted 
population, there was a significantly higher rate of early allograft dysfunction $(p=0.0001)$ when the optimal strategy was not used.

\section{Discussion}

The most used technique of portal decompression during liver transplantation is temporary portocaval shunt. This technique has rapidly spread mainly in European centers as it is an easy and secure technique in most patients. ${ }^{6}$ However, in patients with large segment 1 and most importantly in patients with portal thrombosis and portal cavernoma or in case of important portal hypertension with peribiliary varices and history of upper GI surgery, it may become dangerous or at least may lose its main interest to decrease blood loss.

The technique of mesenterico-saphenous shunt, herein described, enables effective portal decompression without the need for portal pedicle dissection. Indeed it achieves similar hemodynamic efficiency in decompressing the splanchnic area as shown by the analysis of portal pressure decrease at shunt unclamping. Most importantly, it reaches similar results in short-term outcomes particularly in terms of blood transfusion, reperfusion syndrome and early allograft dysfunction. This original technique is as expedient as portocaval shunt with no learning curve as it is derived from mesenteric cannulation as for liver procurement or veno-venous bypass.

As for mesenterico-saphenous shunt, there are some technical limitations to this technique. First, patients who have recurrent ascitic infections may have a difficult access to the inferior mesenteric vein. A small proportion of patients present retroperitoneal venous derivations around this vein rendering its dissection dangerous. In these cases, portocaval shunt may be preferentially used. In retransplanted patients with use of veno-venous bypass during the first $L T$, dissection of the IMV may be tricky especially if the vein has been dissected close to the duodenojejunal angle. Finally this technique has its own complications mainly due to the saphenous access. In our experience, the occurrence of complications in the Scarpa dissection is acceptable. The theoretical risk of shunt 
thrombosis has never led to significant complications, notably venous embolism has not been reported during the study period. It should be noted that the pressure within the shunt progressively achieves a steady state with central venous pressure during the anhepatic phase. Partial clamping of the vena cava is associated to a significant increase in the pressure within the shunt. In this view, pressure measurement through the shunt may be used to monitor the impact of caval clamping.

Surgical portal decompression has been advocated in prospective and randomized trials. They have shown to be associated to better outcomes in terms of transfusion, renal failure and even overall survival. ${ }^{11,12,13}$ Figueras et al. have shown that the benefit of portocaval shunt in terms of renal function was particularly true in patients with increased pre-transplant porto-caval gradient $>16 \mathrm{mmHg}$. These patients may be those without effective spontaneous shunts. Whether the presence and type of spontaneous portosystemic shunts impacts the efficiency of surgical temporary portal decompression has never been specifically addressed in the literature.

Portosystemic shunts are often present in decompensated cirrhotic patients especially in patients with ascites. They may occur in more advanced liver diseases or in liver diseases associated to significant activation of neoangiogenesis. Spontaneous porto-systemic shunts develop according to unknown determinants. However the anatomy of these shunts may be of particular importance when deciding whether portal decompression is indicated. A reasonable hypothesis would be that the development of shunts decrease this gradient and may lower the benefit of portal decompression.

The indication for portal decompression is beyond the scope of this study and we deliberately focused on patients who benefited from a surgical shunt and used the criteria that have been proved to be improved by portocaval shunt in the literature. Indeed although not programmatic, the retrospective data herein presented show that non shunted patients were different from the shunted one. They presented more frequently advanced portal hypertension with spontaneous shunts that led to the absence of significant difference in outcomes as they are actually naturally 
shunted. Short anhepatic phase with portal clamping at the end of the hepatectomy may also lead to the absence of metabolic consequences of splanchnic congestion. However, a higher number of transfused RBC is observed due either to higher blood loss during dissection or to more complex procedures due to more frequent portal thrombosis. One could argue that patients with hemodynamically efficient spontaneous shunts could have been transplanted without any surgical decompression. In a recent series by Azoulay et al., the rate of portal decompression in patients with spontaneous SRS is actually low, reinforcing the idea of lack of need of decompression in the majority of these specific patients. ${ }^{14}$ However the hemodynamic data shown herein underline the variability in spontaneous shunt "hemodynamic efficiency".

An original point of the study is the evaluation of hemodynamic efficiency of spontaneous persistent shunts. First it should be stressed that even in case of large portosystemic shunts portal decompression leads to significant decrease in splanchnic pressure in some cases, revealing a genuine benefit of temporary portal decompression. There seem to be no significant difference in terms of portacaval gradient between the types of spontaneous shunts although proximal shunts seemed associated to higher initial portal pressure and higher decompression efficiency. Although the studied population is small, this observation should be beared in mind. The hemodynamic efficiency of spontaneous shunts may differ according to their anatomical localization and it may be of interest for future studies.

The question of whether portal decompression should be guided by the presence of efficient shunts may be interesting in future studies. Indeed whereas tenants of systematic portal decompression put forward the absence of proven deleterious effect and the existence of evidenced-based medicine data to promote portal decompression, others have shown the feasibility of LT without portal decompression. Besides the question of the role of portal decompression in patients with preexisting shunt - which is beyond the scope of this study - the non shunt tenants put forward a timeconsuming unnecessary surgical step. Given the retrospective aspect of the study, it was not possible 
to compare duration of portocaval shunt and mesenterico-saphenous shunt. The risk of hemorrhagic dissection of the hilar structures in portal hypertension and the shortening of the portal vein for the subsequent portal decompression are other arguments against portocaval shunt. In this view, mesenterico-saphenous shunt may be an elegant alternative that overcomes both limitations.

Proposal for personalized surgical shunt strategy according to spontaneous shunt anatomy (figure 4)

Patients with portal thrombosis could be considered as better candidates for mesenterico-saphenous shunt rather than portocaval shunt given the absence of portal pedicle dissection need. Patients with no persistent shunts should have portal decompression and are considered to benefit in the same way from mesenterico-saphenous shunt and portocaval shunt. No decompression can be considered if there is a spontaneous shunt with a proven hemodynamic efficiency. Portal pressure measurements should therefore be conducted in these cases. However if portal decompression is considered as a routine technique or in specific cases of predicted complex hepatectomy or at the beginning of surgical experience (in order to have time for liver dissection and limit bleeding from the perfused liver), tailored portal decompression is an option. In these cases, patients do not benefit from a surgical shunt when there was a "competing" spontaneous shunt ie a preexisting efficient shunt in the opposite territory, especially in the case of portocaval shunt use which seems particularly dependent on presxisting shunts (inferior mesenteric shunt for portocaval shunt for example). In case of portocaval shunt, ligation of hemodynamically efficient spontaneous shunt should be proposed at the end of liver transplantation.

In conclusion, passive mesenterico-saphenous shunt is a feasible and safe alternative to portocaval shunt that may provide advantages in some particular circumstances. Hemodynamic efficiency of spontaneous and surgical shunts should be evaluated in future studies regarding portal decompression. 
Acknowledgments: we wish to thank Dr Artzner for the language editing and Dr Molière for the CT reconstructions of preoperative portocaval shunts.

The authors declare no conflict of interest and no funding for this study. 
Table 1: description of the 213 included patients according to the type of surgical shunt.

\begin{tabular}{|c|c|c|c|c|c|}
\hline & \multicolumn{2}{|c|}{ Shunted population } & \multirow{2}{*}{$p$ value } & \multirow{2}{*}{$\begin{array}{l}\frac{\text { Non shunted }}{\text { population }} \\
(\mathrm{n}=92)\end{array}$} & \multirow{2}{*}{$\begin{array}{l}\text { p value } \\
\text { (vs shunted) }\end{array}$} \\
\hline & MSS (n=77) & $\operatorname{PCS}(n=44)$ & & & \\
\hline Age & $54 \pm 11$ & $52 \pm 11$ & 0.58 & $55 \pm 10$ & $\underline{0.372}$ \\
\hline Male gender & $53(69 \%)$ & $29(66 \%)$ & 0.741 & $72(78 \%)$ & $\underline{0.09}$ \\
\hline Body mass index $\left(\mathrm{kg} / \mathrm{m}^{2}\right)$ & $25.9 \pm 4$ & $27.7 \pm 5$ & 0.033 & $26.5 \pm 5$ & 0.987 \\
\hline $\begin{array}{l}\text { Etiology of cirrhosis } \\
\text { Alcohol } \\
\text { Hepatitis B } \\
\text { Hepatitis C } \\
\text { Metabolic } \\
\text { Auto-immune } \\
\text { Fulminant hepatitis } \\
\text { Other }\end{array}$ & $\begin{array}{l}39(51 \%) \\
1 \\
15(19 \%) \\
8 \\
2 \\
6\end{array}$ & $\begin{array}{l}27(61 \%) \\
1 \\
7(16 \%) \\
6 \\
4 \\
2\end{array}$ & $\begin{array}{l}0.255 \\
0.624 \\
0.629 \\
\\
0.435\end{array}$ & $\begin{array}{l}\frac{48(52 \%)}{\frac{3}{12}(13 \%)} \\
\frac{11}{\frac{5}{0}} \\
\underline{0}\end{array}$ & $\begin{array}{l}\underline{0.731} \\
\underline{0.311} \\
\underline{0.931} \\
\underline{0.012}\end{array}$ \\
\hline Hepatocellular carcinoma & $22(29 \%)$ & $12(27 \%)$ & 0.879 & $31(34 \%)$ & $\underline{0.406}$ \\
\hline Retransplantation & $1(1 \%)$ & $1(2 \%)$ & 0.686 & $7(8 \%)$ & $\underline{0.032}$ \\
\hline Waiting time (days) & $120 \pm 27$ & $95 \pm 23$ & 0.519 & $\underline{184 \pm 47}$ & $\underline{0.117}$ \\
\hline Lab-MELD at LT & $25.8 \pm 12$ & $27 \pm 11$ & 0.579 & $24 \pm 11$ & 0.171 \\
\hline Lab-MELD >35 & $25(32 \%)$ & $14(32 \%)$ & 0.99 & $20(21 \%)$ & $\underline{0.073}$ \\
\hline Bilirubin at LT (? $? \mathrm{~mol} / \mathrm{L})$ & $168 \pm 23$ & $210 \pm 32$ & 0.276 & $150 \pm 23$ & $\overline{0.283}$ \\
\hline INR at LT & $2.91 \pm 2.4$ & $2.62 \pm 1.3$ & 0.519 & $2.31 \pm 1.3$ & $\underline{0.094}$ \\
\hline Creatinine at LT (?mol/L) & $131 \pm 19$ & $82 \pm 8$ & 0.095 & $\overline{125 \pm 20}$ & $\overline{0.689}$ \\
\hline Pre-LT IL6 $(n=84)$ & $325 \pm 290$ & $44 \pm 8$ & 0.451 & $35 \pm 7$ & $\underline{0.345}$ \\
\hline Ascites & $42(55 \%)$ & $24(55 \%)$ & $>0.99$ & $51(55 \%)$ & $\underline{0.902}$ \\
\hline Platelet count $\left(/ \mathrm{mm}^{3}\right)$ & $91118 \pm 61000$ & $\begin{array}{l}90209 \\
\pm 51000\end{array}$ & 0.935 & $\underline{77147 \pm 7155}$ & 0.200 \\
\hline $\begin{array}{l}\text { Major spontaneous shunt } \\
\text { No major spontaneous shunt }\end{array}$ & $\begin{array}{l}30(43 \%) \\
39(56 \%)\end{array}$ & $\begin{array}{l}22(55 \%) \\
18(45 \%) \\
\end{array}$ & 0.246 & $\begin{array}{l}53(74 \%) \\
19(26 \%) \\
\end{array}$ & $\underline{0.0005}$ \\
\hline $\begin{array}{l}\text { Persistent shunt after portal } \\
\text { clamping }(n=77) \\
\text { Distal persistent shunt } \\
\text { Proximal persistent shunt }\end{array}$ & $\begin{array}{l}21(42 \%) \\
13 \\
8\end{array}$ & $\begin{array}{l}11(49 \%) \\
10 \\
1\end{array}$ & 0.694 & $\begin{array}{l}\underline{61(66 \%)} \\
\underline{38} \\
\underline{23}\end{array}$ & $\underline{0.043}$ \\
\hline $\begin{array}{l}\text { Portal vein thrombosis } \\
\text { Partial thrombosis } \\
\text { Total thrombosis } \\
\end{array}$ & $\begin{array}{l}5(6 \%) \\
4 \\
1 \\
\end{array}$ & $\begin{array}{l}2(5 \%) \\
2 \\
0 \\
\end{array}$ & $\begin{array}{l}0.659 \\
0.495\end{array}$ & $\frac{12(14 \%)}{\frac{10}{2}}$ & $\underline{0.048}$ \\
\hline Extended criteria donor* & $42(55 \%)$ & $28(64 \%)$ & 0.42 & $63(68 \%)$ & $\underline{0.112}$ \\
\hline Donor age & $54 \pm 18$ & $56 \pm 20$ & 0.566 & $61 \pm 17$ & $\underline{0.043}$ \\
\hline
\end{tabular}

* ECD according to EASL definition

MSS : mesenterico-saphenous shunt ; PCS: portocaval anastomosis ; IL6: interleukin-6 
Table 2: hemodynamic efficiency of the 2 types of surgical shunt $(n=51)$

\begin{tabular}{|c|c|c|c|}
\hline & $\operatorname{MSS}(n=31)$ & PCS $(n=20)$ & $p$ value (uni) \\
\hline \multicolumn{4}{|l|}{ Pressures at beginning of $L T$} \\
\hline Portal pressure & $28 \pm 8$ & $30 \pm 7$ & 0.445 \\
\hline Central venous pressure & $13 \pm 5$ & $14 \pm 6$ & 0.459 \\
\hline HVPG & $15 \pm 7$ & $15 \pm 5$ & 0.905 \\
\hline \multicolumn{4}{|l|}{ Pressures at the end of $L T$} \\
\hline Portal pressure & $21 \pm 8$ & $21 \pm 5$ & 0.938 \\
\hline Central venous pressure & $13 \pm 4$ & $13 \pm 5$ & 0.857 \\
\hline HVPG & $8 \pm 5$ & $8 \pm 5$ & 0.934 \\
\hline \multicolumn{4}{|l|}{ Evolution of pressures during $L T$} \\
\hline Portal pressure elevation at clamping & $13.4 \pm 10$ & $9.1 \pm 8$ & 0.125 \\
\hline Decrease in PP after shunt unclamping & $16.3 \pm 11$ & $16.9 \pm 10$ & 0.86 \\
\hline Decrease in PP at the end of LT & $7.7 \pm 2$ & $7 \pm 2$ & 0.78 \\
\hline
\end{tabular}


Table 3: impact of surgical and spontaneous shunt matching on intraoperative and short-term outcomes including patients with available hemodynamic data

\begin{tabular}{|c|c|c|c|}
\hline & No persistent shunt & Persistent distal shunt & Persistent proximal shunt \\
\hline PCS $(n=23)$ & 13 & 9 & 1 \\
\hline Delta PP & $21 \pm 3 \mathrm{mmHg}$ & $12 \pm 4 \mathrm{mmHg} *$ & $17 \mathrm{mmHg}$ * \\
\hline EAD & $50 \%$ & $45 \%$ *\# & $20 \% *$ \\
\hline MSS (n=32) & 20 & & 3 \\
\hline Delta PP & $18 \pm 12 \mathrm{mmHg}$ & $22 \pm 5 \mathrm{mmHg}$ & $13 \pm 4 \mathrm{mmHg}$ \\
\hline EAD & $45 \%$ & $23 \%^{\#}$ & $19 \%$ \\
\hline
\end{tabular}

$* p=0.002$

${ }^{\#} p=0.047$ 
Table 4: intraoperative data and outcomes according to the type of surgical shunt

\begin{tabular}{|c|c|c|c|c|c|}
\hline & \multicolumn{2}{|c|}{$\begin{array}{l}\text { Shunted population } \\
(n=121)\end{array}$} & \multirow[t]{2}{*}{$p$ value } & \multirow[t]{2}{*}{$\frac{\text { Non shunted }}{\text { population }(n=92)}$} & \multirow[t]{2}{*}{ p value } \\
\hline & SMS ( $n=77)$ & PCS $(n=44)$ & & & \\
\hline Cold ischemia time (minutes) & $497 \pm 117$ & $445 \pm 101$ & 0.016 & $457 \pm 92$ & $\underline{0.344}$ \\
\hline Anhepatic phase (minutes) & $98 \pm 45$ & $104 \pm 41$ & 0.474 & $79 \pm 39$ & $\leq 0.0001$ \\
\hline Operative time (minutes) & $366 \pm 126$ & $316 \pm 98$ & 0.036 & $315 \pm 94$ & $\leq 0.0001$ \\
\hline $\begin{array}{l}\text { Reperfusion syndrome } \\
(\mathrm{n}=145)\end{array}$ & $21(44 \%)$ & $19(43 \%)$ & 0.956 & $24(45 \%)$ & $\underline{0.833}$ \\
\hline ASAT at unclamping & $1267 \pm 1409$ & $1018 \pm 801$ & 0.304 & $\underline{1208 \pm 1782}$ & $\underline{0.88}$ \\
\hline ALAT at unclamping & $793 \pm 648$ & $684 \pm 540$ & 0.365 & $\underline{786 \pm 1007}$ & $\underline{0.781}$ \\
\hline $\mathrm{K}+$ at unclamping & $3.74 \pm 0.7$ & $3.75 \pm 0.8$ & 0.922 & $\underline{3.82 \pm 0.8}$ & $\underline{0.496}$ \\
\hline $\begin{array}{l}\text { Lactates at unclamping } \\
(\mu \mathrm{mol} / \mathrm{L})\end{array}$ & $4.78 \pm 2.7$ & $3.42 \pm 2.3$ & 0.009 & $3.67 \pm 2$ & $\underline{0.096}$ \\
\hline IL6 at unclamping & $1450 \pm 615$ & $663 \pm 112$ & 0.328 & $\underline{1942 \pm 1152}$ & $\underline{0.480}$ \\
\hline RBC units* & $6(0-18)$ & $6(0-21)$ & 0.575 & $\underline{8(0-40)}$ & $\underline{0.049}$ \\
\hline FFP units* & $8(0-24)$ & $7(0-32)$ & 0.89 & $\underline{11(0-36)}$ & $\underline{0.13}$ \\
\hline Platelets concentrates* & $0.5(0-6)$ & $0(0-5)$ & 0.922 & $1.5(0-12)$ & $\underline{0.066}$ \\
\hline Primary non function & $0(0 \%)$ & $1(2 \%)$ & 0.184 & $\underline{0(0 \%)}$ & $\underline{0.382}$ \\
\hline Early allograft dysfunction & $19(25 \%)$ & $11(25 \%)$ & 0.976 & $30(35 \%)$ & $\underline{0.114}$ \\
\hline Day 7 bilirubin $(\mu \mathrm{mol} / \mathrm{L})$ & $79 \pm 10$ & $90 \pm 10$ & 0.508 & $103 \pm 13$ & $\underline{0.174}$ \\
\hline Day 7 INR (IU) & $1.19 \pm 0.2$ & $1.34 \pm 1$ & 0.198 & $1.3 \pm 0.4$ & $\underline{0.446}$ \\
\hline Peak ASAT d1-d7 & $660 \pm 153$ & $868 \pm 153$ & 0.252 & $984 \pm 257$ & 0.302 \\
\hline Peak ALAT d1-d7 & $710 \pm 74$ & $729 \pm 89$ & 0.877 & $\underline{709 \pm 672}$ & $\underline{0.971}$ \\
\hline 90-day mortality & $4(5 \%)$ & $3(7 \%)$ & 0.716 & $12(13 \%)$ & $\underline{0.061}$ \\
\hline Ventilation duration (days) & $4 \pm 1$ & $4 \pm 1$ & 0.92 & $\underline{5 \pm 1}$ & $\underline{0.876}$ \\
\hline Necessity of reintubation & $15(21 \%)$ & $8(19 \%)$ & 0.819 & $14(15 \%)$ & $\underline{0.245}$ \\
\hline $\begin{array}{l}\text { Acute kidney injury (within } 15 \\
1^{\text {st }} \text { days) }\end{array}$ & $44(66 \%)$ & $24(55 \%)$ & 0.239 & $\underline{63(68 \%)}$ & $\underline{0.152}$ \\
\hline $\begin{array}{l}\text { Need for postoperative } \\
\text { dialysis }\end{array}$ & $20(29 \%)$ & $12(27 \%)$ & 0.627 & $\underline{36 \%}$ & $\underline{0.205}$ \\
\hline
\end{tabular}




\footnotetext{
${ }^{1}$ Belghiti J, Noun R, Sauvanet A. Temporary portocaval anastomosis with preservation of caval flow during orthotopic liver transplantation. Am J Surg;1995;169:277-279

${ }^{2}$ Tzakis AG, Reyes J, Nour B, et al. Temporary end to side portacaval shunt in orthotopic hepatic transplantation in humans. Surg Gynecol Obstet.1993;176(2):180-182

${ }^{3}$ Figueras J, Llado L, Ramos E, et al. Temporary portocaval shunt during liver transplantation with vena cava preservation. Results of a prospective randomized study. Liver Transpl.2001;7(10):904-911

${ }^{4}$ Paugam-Burtz C, Kavafyan J, Merckx $\mathrm{P}$ et al. Portreperfusion syndrome during liver transplantation for cirrhosis : outcome and predictors. Liver Transpl. 2009;15:522-29

${ }^{5}$ Miyata T, Yokoyama I, Todo $S$ et al. Endotoxinemia, pulmonary complications and thrombocytopenia in liver transplantation. Lancet. 1989;189-91

${ }^{6}$ Kluger MD, Memeo R, Laurent A et al. Survey of adult liver transplantation techniques (SALT) : an international study of current practices in deceased donor liver transplantation. HBP.2011;13:692-98

${ }^{7}$ Muscari F, Suc B, Aguirre J et al. Orthotopic liver transplantation with vena cava preservation in cirrhotic patients: is systematic temporary portacaval anastomosis a justified procedure? Transplant Proc.2005;37(5):2159-62

${ }^{8}$ Lerut J, Ciccarelli O, Roggen $\mathrm{F}$ et al. Cavocaval adult liver transplantation and retransplantation without venovenous bypass and without portocaval shunting: a prospective feasibility study in adult liver transplantation. Transplantation.2003;27(10):1740-5

${ }^{9}$ Saad WEA. Vascular anatomy and the morphologic and hemodynamic classifications of gastric varices and spontaneous portosystemic shunts relevant to the BRTO procedure. Tech Vasc Interv Radiol.2013;16(2):60-100

${ }^{10}$ Olthoff KE, Kulik L, Samstein B et al. Validation of a current definition of early allograft dysfunction in liver transplant recipients and analysis of risk factors. Liver Transpl.2010;16:943-49

${ }^{11}$ Ghinolfi D, Marti J, Rodriquez-Laiz G eta I. The beneficial impact of temporary porto-caval shunt in orthotopic liver transplantation: a single center analysis. Transpl Int.2011;24(3):243-50

12 Arzy GD, De Ruvo N, Montalti R et al. Temporary porto-caval shunt utility during orthotopic liver transplantation. Transplant proc.2008;40(6):1937-40

${ }^{13}$ Pratschke S, Meimarakis G, Bruns CJ et al. Temporary intraoperative portaocaval shunt : useless or beneficial in piggy back liver transplantation. Transplant Int.2012;26(1):90-8

${ }^{14}$ Gomez-Gavara C, Banghi P, Salloum C, Osseis M, Esposito F et al. Ligation vs no ligation of spontaneous porto-systemic shunts during liver transplantation: audit of a prospective series of 66 consecutive patients. Liver Transpl.2017.doi:10.1002/It.24999
} 


\section{Figure legend}

Figure 1: intraoperative views of the $\mathbf{2}$ types of surgical shunts; on the left panel: portocaval anastomosis ; on the right panel: mesenterico-saphenous shunt

Figure 2: impact of the anatomy of spontaneous portosystemic shunts on surgical shunt efficiency. Portal pressure decrease after surgical shunt opening is significantly lower in patients receiving PCS in case of distal shunt (left panel). MSS hemodynamic efficiency does not seem dependent on spontaneous shunt anatomy. (Prox: proximal preexisting shunt ; $\mathrm{N}$ : no or non persistent shunt ; Dist: distal preexisting shunt)

Figure 3: short-term outcomes in terms of day 7 bilirubin (left panel) and transaminases peak (right panel) according to the respect of the proposed surgical shunt strategy in regard to portosystemic shunts anatomy. There was a significantly higher risk of Early Allograft Dysfunction when surgical shunt decompression was predicted to be inefficient according to the competing shunt hypothesis

Figure 4: proposed algorithm for tailored portal decompression; patients with portal thrombosis could be shunted with MSS to decrease portal pressure and enable safe portal thrombectomy with decompressed mesenteric pressure. Patients with persistent and hemodynamically efficient shunt, no portal decompression can be proposed. However some circumstances may indicate the use of portal decompression. In these cases, anatomy of the shunts should be carefully analyzed on preoperative $\mathrm{CT}$ to choose the most efficient way to achieve portal decompression.

MSS: mesenterico-saphenous shunt; PCS: portocaval shunt 

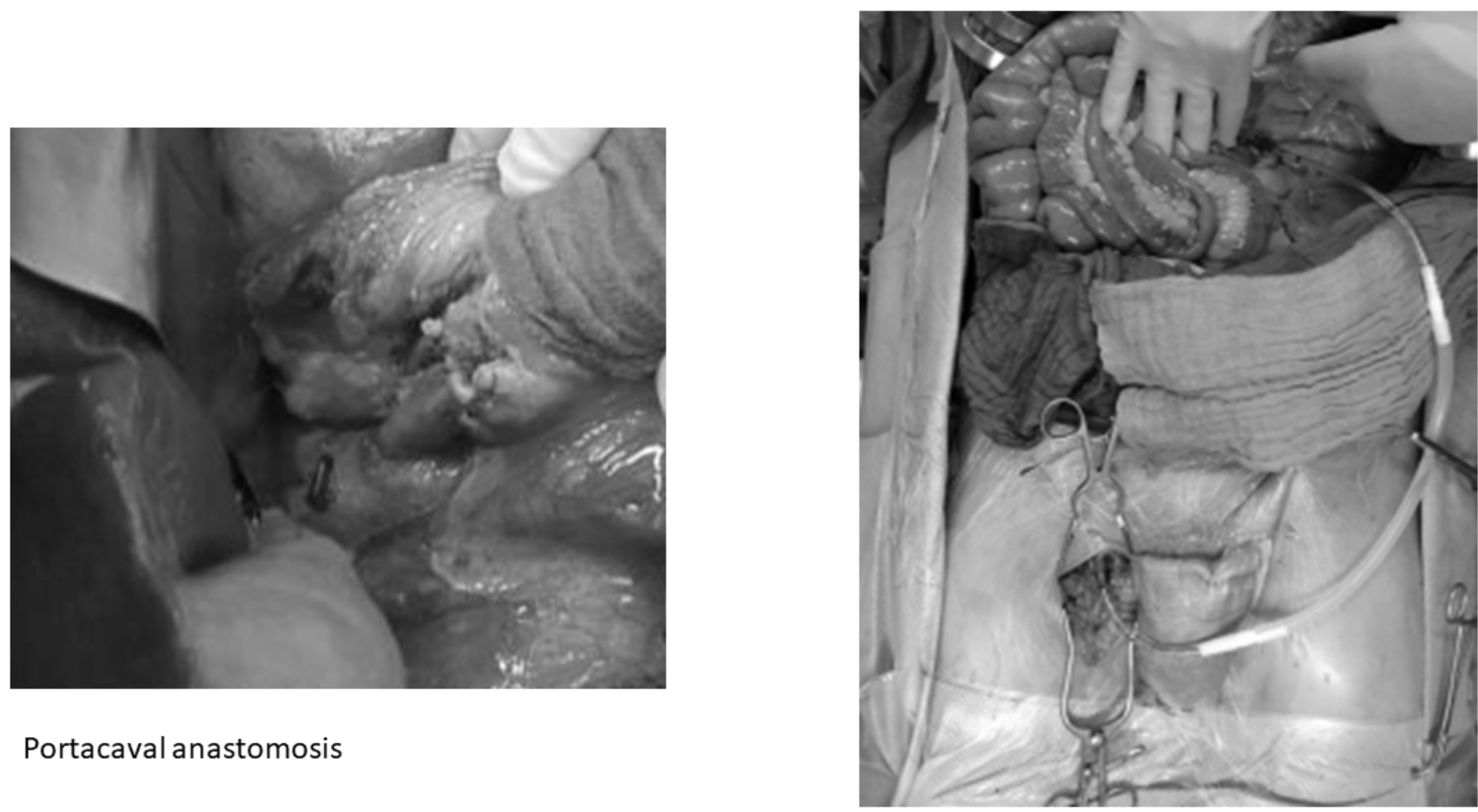

Portacaval anastomosis 


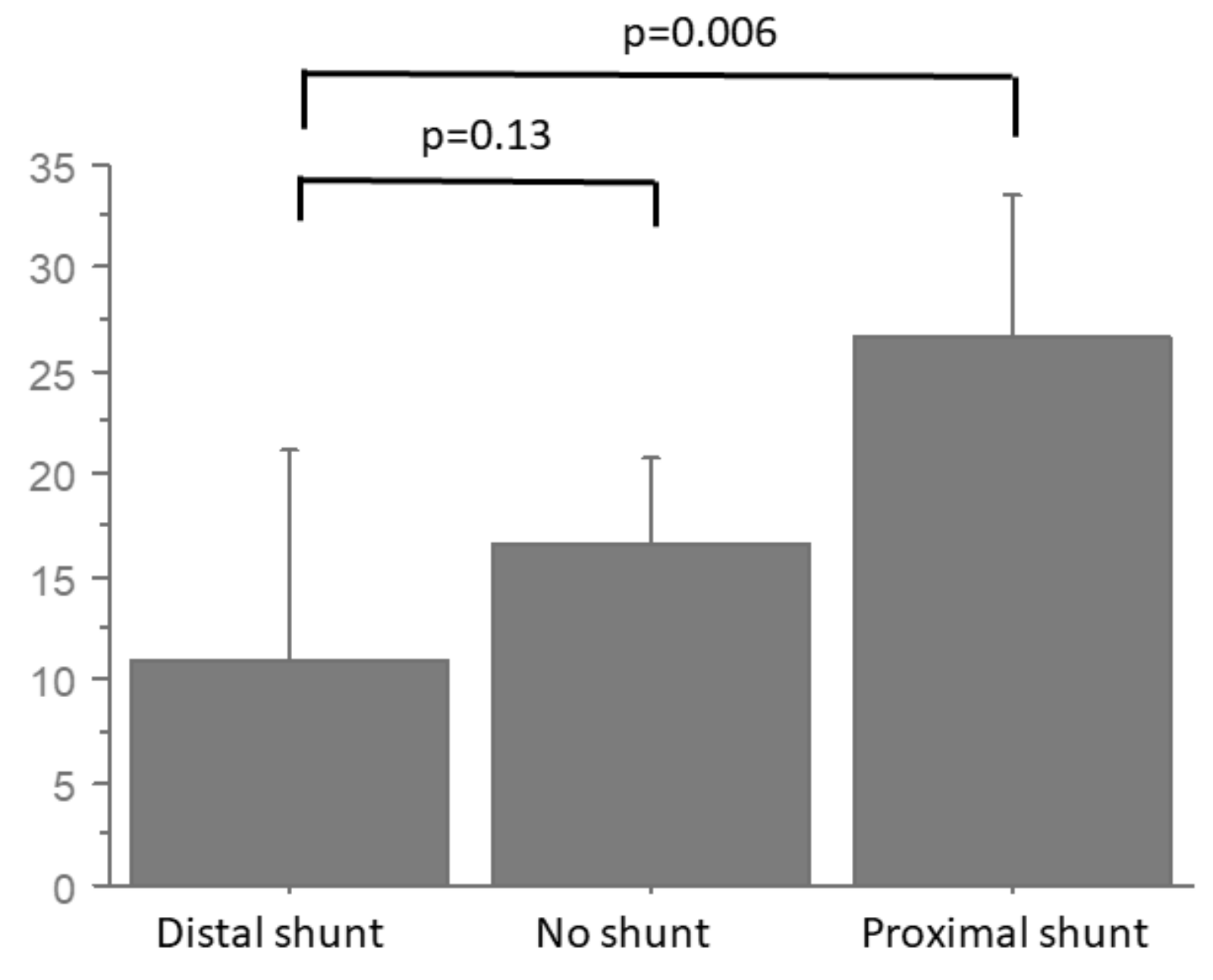

Delta portal pressure with PCS

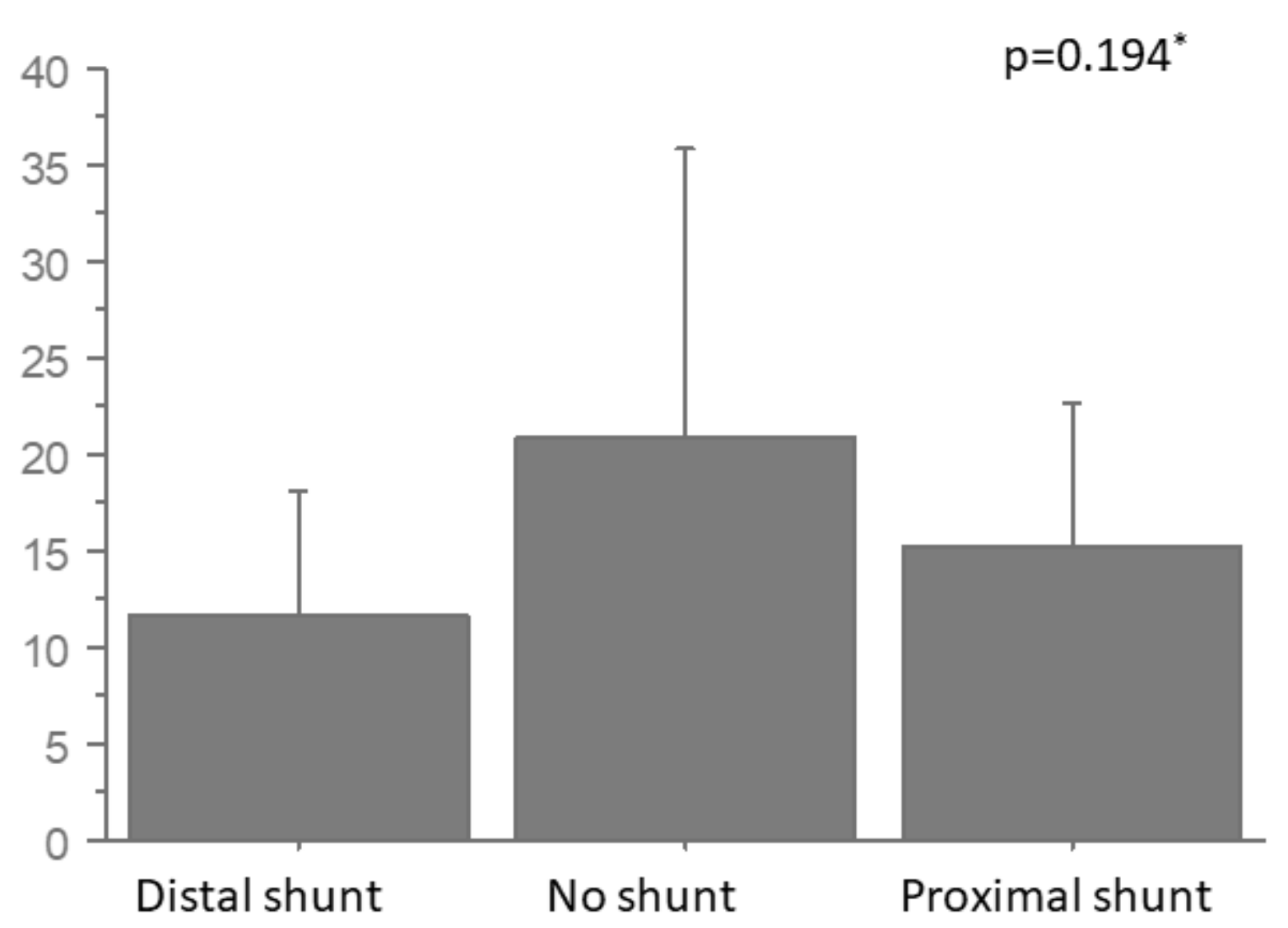

Delta portal pressure with MSS 

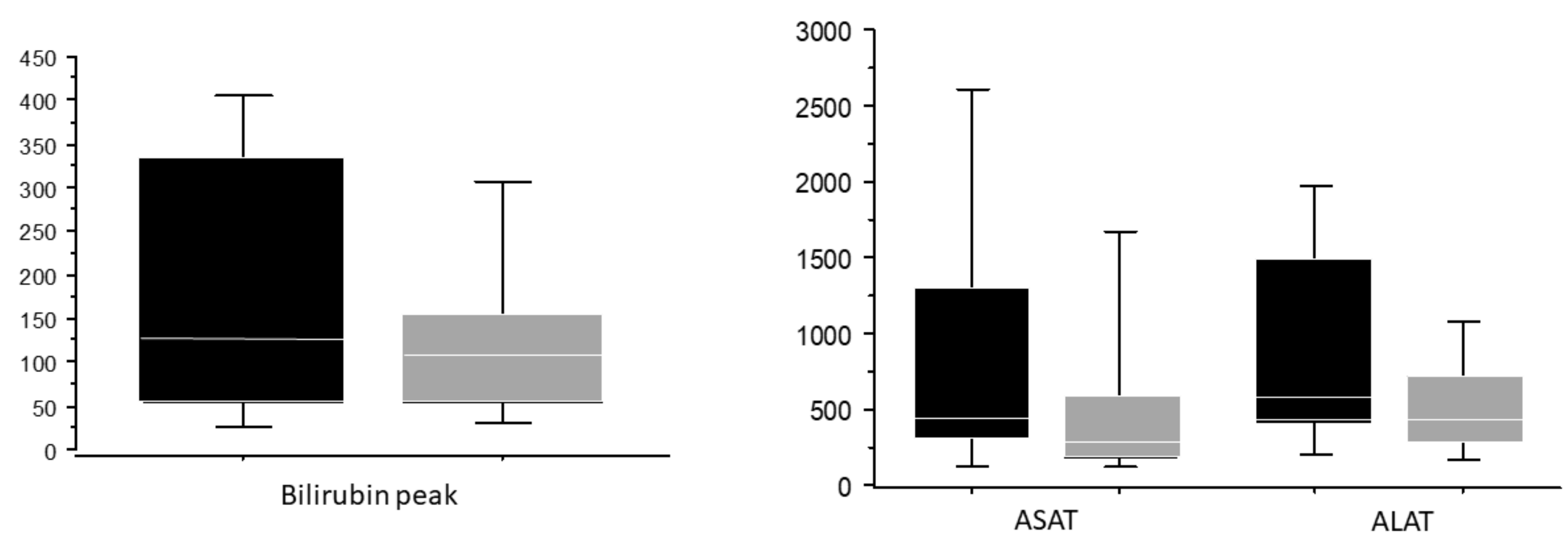


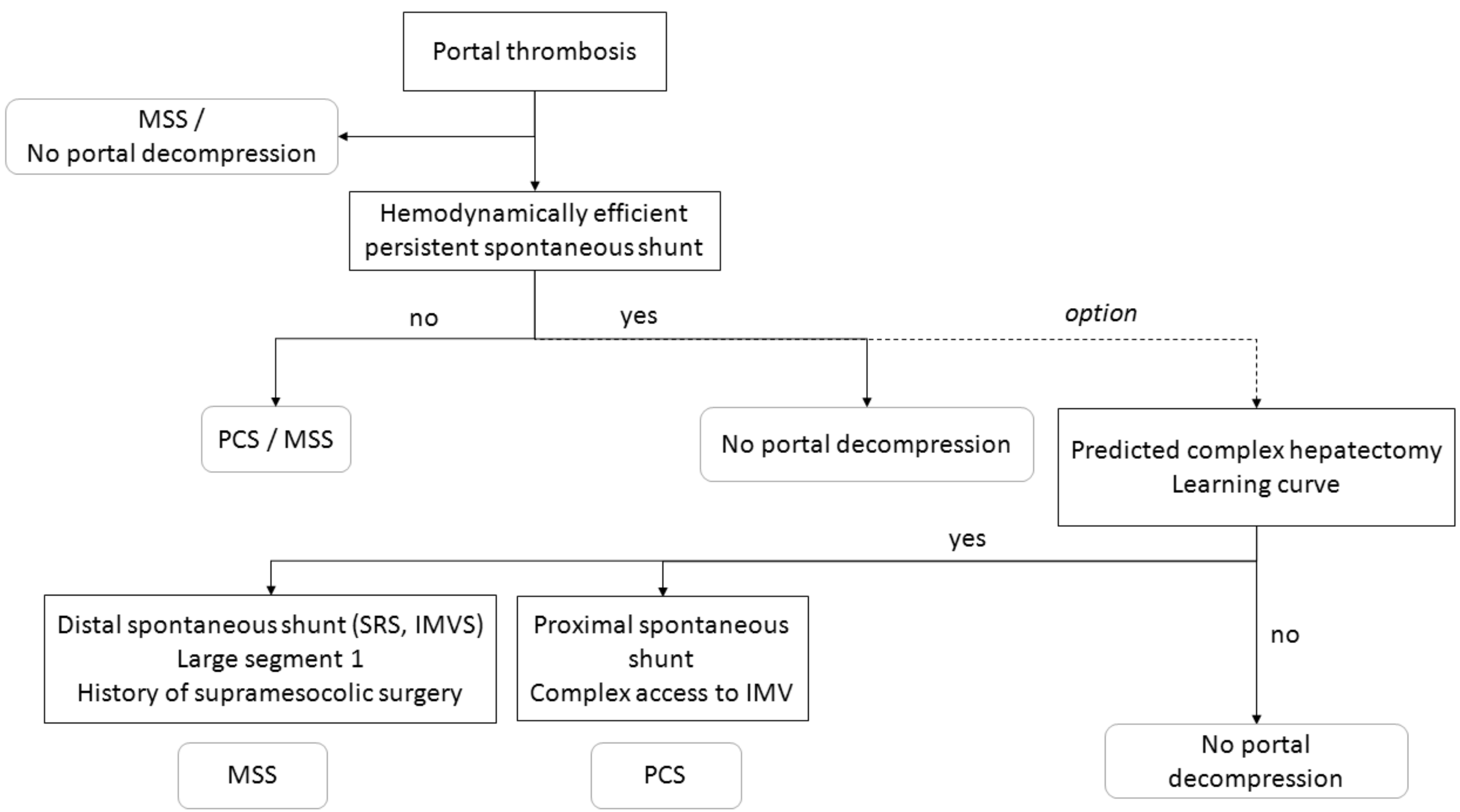

